\title{
Recurrent intussusception as a rare clinical manifestation of intestinal malrotation in children - a case report and review of literature
}

Aditya Arvind Manekar, Narahari Janjala, Subrat Kumar Sahoo, Bikasha Bihary Tripathy and Manoj Kumar Mohanty

\begin{abstract}
Background: Mobile caecum along with malfixed small bowel mesentery in malrotation is incriminated to cause intussusception in children. This dual association is very rare and is labeled as Waugh's syndrome. This is often missed during conservative management of intussusception and may manifest as chronic intussusception.

Case presentation: We report a rare case of intestinal malrotation in a 13-year-old boy who presented as recurrent intussusception. The child was resuscitated and was operated, where malrotation of gut was detected. We discuss the clinical presentation, radiological findings, and management of this rare association in light of current available literature.

Conclusion: The presence of mobile caecum and redundant bowel loops with narrow mesentery in case of malrotation is an important factor leading to intussusception.
\end{abstract}

Keywords: Waugh's syndrome, Mobile caecum, Ladd's procedure

\section{Background}

Acute intussusception is a common surgical emergency in children. It is the telescoping of one part of the bowel into another part next to it. They usually present as small bowel obstruction with colicky abdominal pain, vomiting, abdominal distension, and bloody stool. Sometimes, it may be transient or may reduce spontaneously. However, malrotation of the intestine is a congenital condition caused due to an abnormal rotation and fixation of the bowel. In 1911, Geo. E. Waugh first described the causal association between intestinal malrotation and intussusception [1]. It was coined as Waugh's syndrome by Brereton et al. [2] after confirming up to $40 \%$ association in their prospective study. Since then, a few case reports were published describing this rarely reported entity.
Chronic intussusception is a distinct clinical entity of non-strangulating and incompletely obstructing intussusception that is poorly recognized and rarely described. It is characterized by intermittent attacks of abdominal pain lasting more than 14 days with or without other symptoms of acute intussusception [3]. They have significant weight loss due to long-standing anorexia and vomiting [4]. However, recurrent intussusception is preceded by a similar illness or a recurrence occurring after a successful reduction [4].

We report a case presented to us as recurrent intussusception and its association with intestinal malrotation was detected during laparotomy for surgical reduction of intussusception. We shall briefly discuss the causal association between recurrent intussusception and intestinal malrotation and review the literature.

* Correspondence: pedsurg_manoj@aiimsbhubaneswar.edu.in

Department of Paediatric Surgery, All India Institute of Medical Sciences,

Bhubaneswar, India 


\section{Case presentation}

A 13-year-old male child was referred to our emergency department with complaints of intermittent, colicky abdominal pain since last 3 days, with 2 episodes of bilious vomiting and abdominal distension for 1 day. The child was admitted in a peripheral hospital 3 days ago and was conservatively treated with IV antibiotics and analgesics. He had a history of multiple episodes of abdominal pain during last 6 months which subsided with medications. During one such episode, he was diagnosed of having ileo-colic intussusception by ultrasonography elsewhere; which reduced spontaneously next day without any active intervention as confirmed by ultrasonography.

On examination, he was dehydrated, vitals were stable. His weight and height were less than the standard for his age. Clinically, there was mild distension with guarding and tenderness all over the abdomen. A sausageshaped lump was palpable in the right lower and upper quadrants (Fig. 1). Digital rectal examination revealed an empty rectum with no stool.

Routine blood investigations were normal. Erect abdominal radiograph depicted dilated jejunal loops with multiple air-fluid levels without any gas shadow in the pelvis (Fig. 2a). Nasogastric tube aspiration showed bilious contents. Ultrasound examination revealed ileocolic intussusception of about $12 \mathrm{~cm}$ in length, with dilated small bowel loops, sluggish peristalsis, and mild free fluid in the abdomen (Fig. 2b).

The child was resuscitated with IV fluids and antibiotics. Exploratory laparotomy was performed which showed dilated jejunal and ileal loops with a long segment of ileo-ileal intussusception (Fig. 3a). To our utter surprise, we detected malrotation of the small bowel with ileo-colic junction in the left upper abdomen, Ladd's bands going from the caecum and ascending colon compressing the duodenum to the right flank, and the duodeno-jejunal junction on the right side of the midline (Fig. 3b).

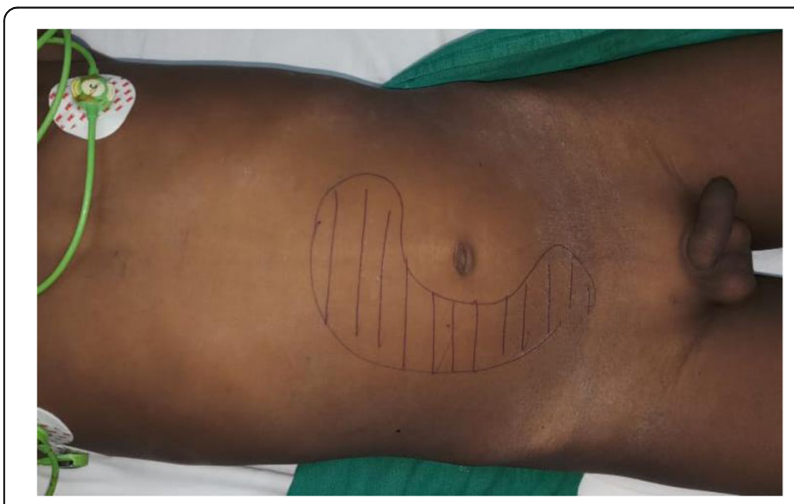

Fig. 1 Clinical photograph of the abdomen
Intussusception was reduced manually, and Ladd's procedure was done with complete division of the Ladd's bands, straightening of the C-loop of duodenum and widening of the mesentery up to its attachment along with an inversion appendectomy. The small bowel loops were replaced in the right side and large bowel in the left side of the abdomen. The child had an uneventful postoperative recovery and was discharged on 6th postoperative day. He had gained weight and doing well during follow-up.

\section{Discussion}

Acute intussusception is a common abdominal emergency in children, presenting with intermittent abdominal pain, vomiting, and red currant jelly stool. In 1911, Waugh first described the association between intestinal malrotation and intussusceptions [1]. Since then, very few cases of infantile Waugh's syndrome have been reported in the literature [5].

There is no lead point in Waugh's syndrome. The presence of abnormally placed gut loops with narrow mesentery along with unfixed and mobile caecum and ascending colon in malrotation might be a precursor for intussusception. Brereton et al. [2] named this association of intussusception and malrotation as Waugh's syndrome and suggested that malfixation of the ileocecal mesentery is a leading factor in allowing intussusception. Waugh originally suggested that an ascending and descending colon relatively unfixed to the posterior wall and freely suspended by its primitive mesenteric folds may provoke ileocecal intussusception [1]. Zavaras N. et al. had incriminated the possible role of the freely mobile ileocecal junction as a principal factor of chronic intussusception [3].

Patients with intussusceptions are best managed by pneumatic or hydrostatic reduction [6]. In our case, the 13-year-old child presented with a long history of 3 days and signs of peritonitis; hence, an open emergency laparotomy was considered. Around 95\% of intussusceptions in children are idiopathic. Pathologic lead points are detected in only a few patients; Meckel's diverticulum is the most common [6]. Our patient had no pathological lead point, neither detected on ultrasound nor during laparotomy. Malrotation of the gut was missed in our case during the previous episode of conservative management for intussusception.

The exact frequency of Waugh's syndrome is not known [7]. However, in their prospective study, Brereton et al. reported an atypically positioned duodeno-jejunal junction in $40 \%$ of patients with intussusception [2]. Waugh's syndrome is often missed in case of close reduction of intussusception, and this may be a reason for recurrence of intussusception [8]. 


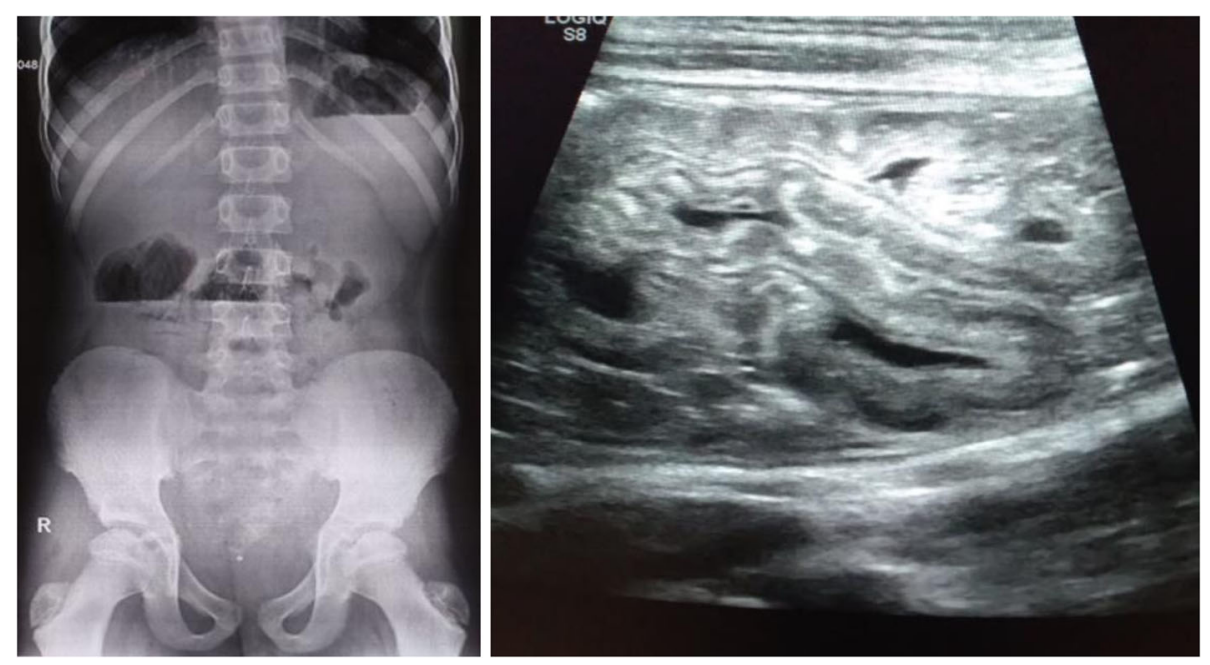

Fig. 2 a X-ray erect abdomen and pelvis of the patient. $\mathbf{b}$ Ultrasonography image showing the intussusception with an edematous thickened bowel wall

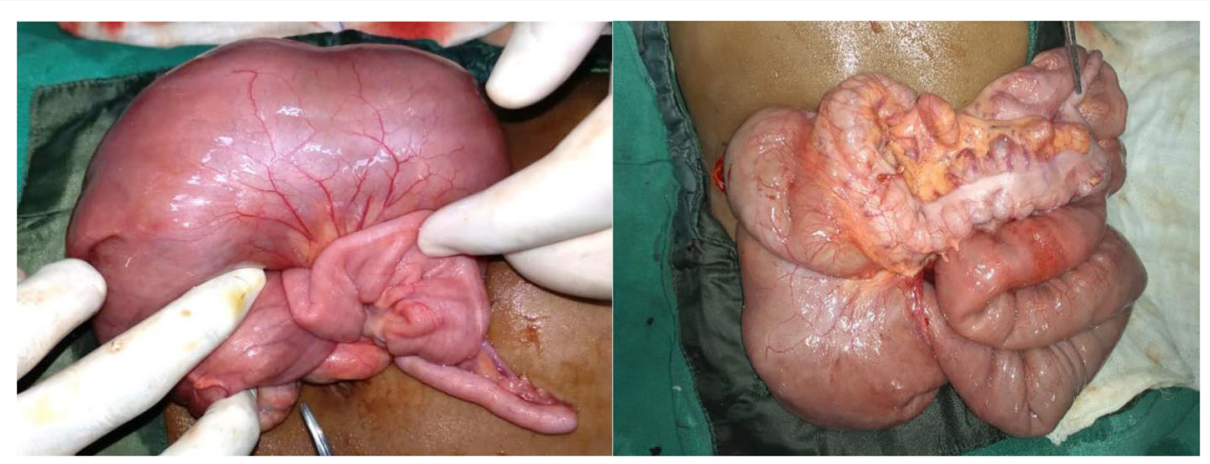

Fig. 3 a Dilated jejunum with normal appendix and caecum. b Dilated small bowel with normal appendix in left upper quadrant with presence of Ladd's bands 


\section{Conclusions}

It is postulated that the presence of mobile caecum and redundant bowel loops with narrow mesentery in case of malrotation is an important factor leading to intussusception. A high degree of clinical suspicion is necessary for this dual condition. The possibility of Waugh's syndrome should always be kept in mind when a case of intussusception is being treated by either operative or non-operative method.

\section{Acknowledgements}

Dr. Amrapali Vedpathak Manekar, wife of Dr. Aditya Arvind Manekar, for her tremendous support in course of the manuscript preparation.

\section{Authors' contributions}

AAM: manuscript preparation. NJ: manuscript preparation. SKS: clinical management. BBT: clinical management. MKM: manuscript review and submission. All authors have approved the manuscript.

\section{Funding}

None

Availability of data and materials

During the course of treatment

\section{Declarations}

Ethics approval and consent to participate

Obtained from the institute

\section{Consent for publication}

Obtained from the father of the child

\section{Competing interests}

The authors declare that they have no competing interest.

Received: 26 November 2020 Accepted: 24 June 2021

Published online: 04 October 2021

\section{References}

1. Waugh GE. Referred penile pain in intussusception with notes of three cases. Lancet. 1911;:1:1492-4.

2. Brereton RJ, Taylor B, Hall CM. Intussusception and intestinal malrotation in infants: Waugh's syndrome. Br J Surg. 1986;73(1):55-7. https://doi.org/10.1 002/bjs.1800730123.

3. Zavras N, Tsilikas K, Vaos G. Chronic intussusception associated with malrotation in a child: a variation of Waugh's syndrome? Case Rep Surg. 2016;2016:5638451.

4. Rees BI, Lari J. Chronic intussusception in children. Br J Surg. 1976;63(1):335. https://doi.org/10.1002/bjs.1800630108.

5. Baltazar G, Sahyoun C, Sime J, Bitar M, Bitar J, Rao AC. Discovery of a case of Waugh's syndrome during a mission to Haiti. Int I Surg Case Rep. 2012;3(1): 22-4. https://doi.org/10.1016/j.ijscr.2011.09.006.

6. Columbani PM, Scholz S. Intussusception. In: Coran AG, Adzick NS, Krummel TM, Laberge JM, Shamberger RC, Caldamone AA, editors. Paediatric Surgery. 7th ed: Elsevier Saunders; 2012. p. 1093-110.

7. Khan YA, Yadav SK, Elkholy A. Waugh's syndrome: report of two children with intussusception. European J Pediatr Surg Rep. 2017 Jan;5(1):e29-31.

8. Behera CR, Mohanty SK. Waugh's syndrome: blessing in disguise. J Clin Diagn Res. 2014;8(10):ND26-7. https://doi.org/10.7860/JCDR/2014/9557.5051.

\section{Publisher's Note}

Springer Nature remains neutral with regard to jurisdictional claims in published maps and institutional affiliations.

\section{Submit your manuscript to a SpringerOpen ${ }^{\circ}$ journal and benefit from:}

- Convenient online submission

- Rigorous peer review

- Open access: articles freely available online

High visibility within the field

- Retaining the copyright to your article

Submit your next manuscript at $\boldsymbol{\nabla}$ springeropen.com 